\title{
THREE-WAY ATTACK ON AIDS VIRUS: VACCINES, IMMUNE SERA, SCREENING
}

\section{By Tazewell Wilson}

1 Ithough the recent discovery of two retroviruses closely linked to acquired immunodeficiency syndrome (AIDS) is a major step in tracingand therefore controlling-the epidemiology of this disease, it offers scant hope for AIIS victims. Discovery of a causative agent rarcly begets an immediate cure. Nevertheless, identification of the putative AIDS agents (which many researchers think are the same or minor variants of the same virus) holds real promise for diagnosis and prevention of the disease.

The evidence linking the viruses to AIDS is circumstantial but compelling. HTI.V-III, the virus isolated by Robert Gallo (National Cancer Institute, Bethesda, MI)) and his collaborators, sclectively infects and kills helper $\mathrm{T}$ lymphocytes, cells that are virtually absent in AIDS patients. Nearly all patients with AIDS or the AIDS-related lymphoadenopathy syndrome have antibodies to HTLV. III or to LAV, the virus identified by a group led by JeanClaude Chermann and Luc Montagnier (Institut Pasteur, Paris). Many also have virus in their blood. However, researchers caution that AIDS is complicated; it may well involve other forms of immune suppression, and perhaps even other infectious agents.

Ilaving identified and isolated the virus, researchers and public health authorities can now devise a rational strategy for controlling its spread. A simple test for antibodies against the virus, which indicate a person has been infected, should be available to screen blood supplies and high-risk individuals in the L.S. by the end of this year. Neutralizing antibodies from "immune serum" or selected hybridomas may be used to confer passive immunity temporarily. But the best hope for long-term control of AIDS is a vaccine that will protect high-risk individuals from infection by the virus.

Officials from the U.S. Department of Health and Human Services (DHHS) predict that an AIDS vaccine will be available for testing in two to three years-unprecedented speed considering how little is known about the virus. That researchers are cautiously optimistic they can achieve this goal is a demonstration of just how powerful the techniques of biotechnology have become.

The technical difficulties in developing an AIDS vaccine are formidable. For example, researchers do not yet know how the virus is transmitted within the body or how it causes the devastating breakdown of the immune system that characterizes AIDS. "We do have some experience with related viruses, though," says Max Essex (Harvard Medical School, Boston, MA). "We have been studying the main immunogenic protein of HTLV-I, which has some cross-reactivity with IITLV-III. We think we can use the information about this protein to get a product that should be protective."

I.AV and H'T.V-III are retroviruses, a diverse family of viruses associated with cancer in many animals. Retroviruses have complicated life cycles and their role in human discase is still not well understood. Because different retroviruses have different modes of transmission, some are more easily attacked by antibodies than others. "Before talking about a vaccine you need to know how the virus is transmitted," explains Howard I'emin (Lniversity of Wisconsin).
The immediate obstacle to vaccine development is the lack of a testing system. There is no good animal model for AIDS, nor is there a way to assay for neutralization of the virus' infectivity. Researchers hope to find a nonhuman primate susceptible to LAV/HTLV-III infection. But AIDS symptoms in humans sometimes don't appear until several years after a primary infection and may well be linked to precipitating cofactors. Thus prospects for a good animal model for vaccine testing are dim. With lethal diseases like AIDS, however, animal models may not be essential-people in high-risk groups are often willing to test the vaccine without animal trials.

Development of a test for neutralization of the virus is essential because protection from infection requires neutralizing antibodics. The problem is that not all antibodies directed against a virus neutralize its infectivity. Most AIDS patients tested have antibodies to HILV-III, but the antibodies fail to protect them from the disease.

$A$ successful vaccine must stimulate the body to produce antibodies that not only recognize the virus, but also disarm it. Thus researchers need to find a way to detect LAV/HTI.V-III neutralizing antibodies, then identify the antigens that elicit them. Jerome Groopman (Harvard Medical School) has identified a number of antibodypositive, healthy individuals who may have developed neutralizing antibodies that protect them from the virus, but his studies are not yet complete.

If scientists can identify people producing neutralizing antibodies, it may be possible to transfer their immunity to potential $\Lambda$ IDS victims. "Immune serum" containing the antibodies can be used to passively. immunize high-risk individuals. Alternatively, it may be possible to produce monoclonal antibodies that neutralize the virus and can be administered prophylactically. Passive immunity is only temporary, however. There are no antibody-producing cells to replace the proteins as they are cleared from the recipient's blood.

While strategies like passive immunization and screening certainly have short-term value, the only effective way to control infectious diseases like AIDS is vaccination.

No one, however, knows exactly how to design an effective vaccine against a virus whose life cycle is still mysterious. LAV/HTLV-III does not appear to behave like most well-studied retroviruses: it kills rather than transforms its target cells. (Researchers do not yet know whether the virus itself is cytotoxic or whether it turns infected cells into targets for cytotoxic lymphocytes.) If the virus spreads via free particles in the blood, it may be possible to halt the infectious cycle by immunization.

Immunization against retroviruses does not always produce predictable results. For example Norden Laboratories (Lincoln, NB) is producing a vaccine against feline leukemia virus ( $\mathrm{FeLV}$ ), a retrovirus that infects many cats but does not always cause leukemia. William Beckenhauer, vice-president for biological $\mathrm{R} \& \mathrm{I}$ ) at Norden, explains that the vaccine works in an unusual way. "It does not seem to restrict multiplication of FeL.V-vaccinated animals often produce high titers of virus-but the vaccinated cats do not develop leukemia."

The vaccine being developed by Norden would not be suitable for human use. It is made from virus-producing 


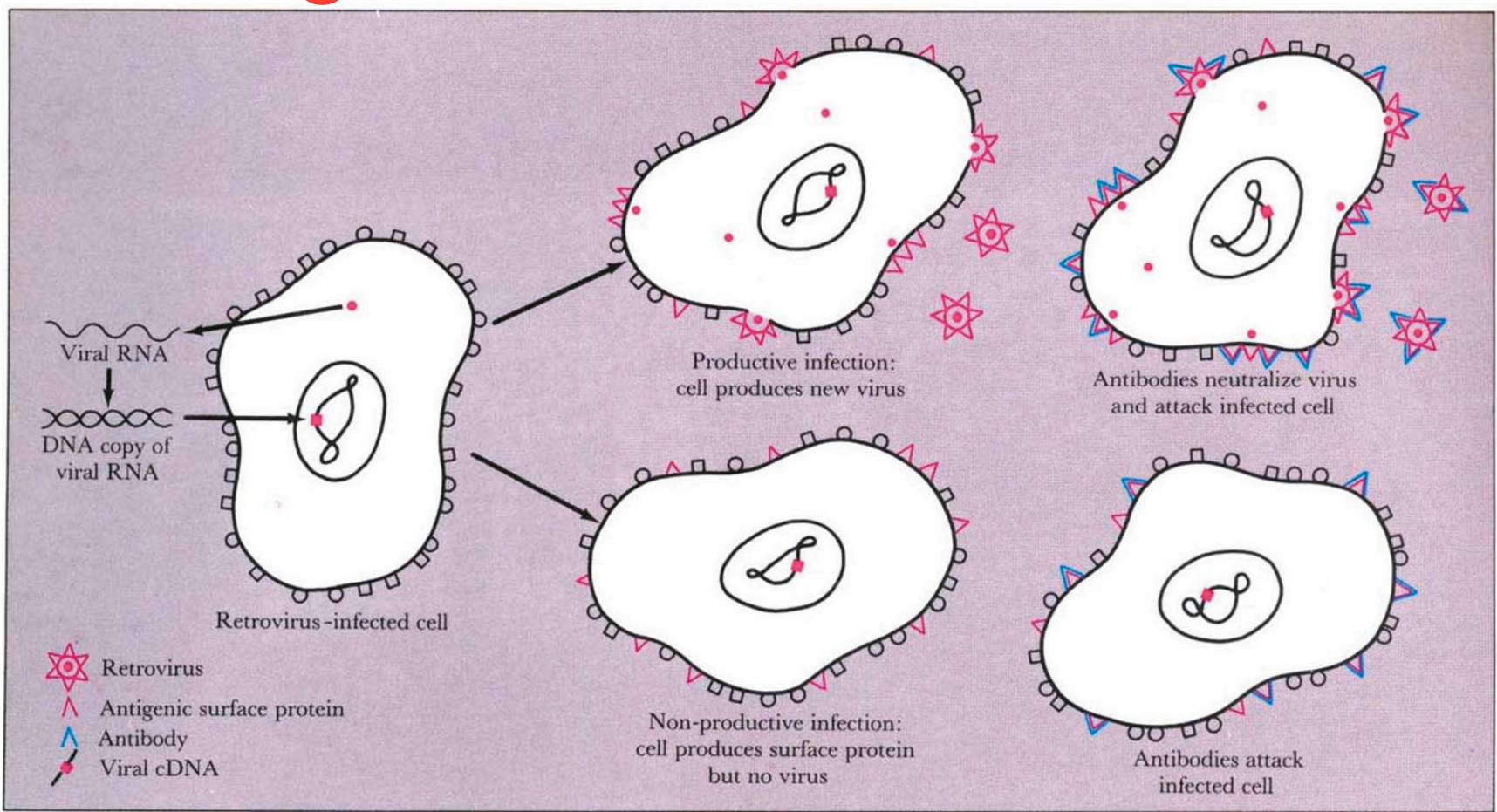

Retroviruses have a RNA-protein core surrounded by a membranous envelope displaying the surface proteins that elicit most antibodies. After infecting a cell, the virus produces DNA copies its RNA. Some of the copies insert into the cell's DNA. If the virus establishes a productive infection, the cell reproduces all the viral components. If the infection is nonproductive, only a few viral components are synthesized. Virus-specific antibodies can neutralize the new virus and/or attack infected cells.

cell cultures and contains impurities such as cell fragments. In fact, most scientists think it unlikely that a vaccine against a human retrovirus would come from whole virus at all. "The chances for contamination are just too great," explains Erwin Fleissner (Memorial Sloan Kettering, New York, NY). Moreover, most retroviruses are oncogenic. HTLV-I, a human retrovirus related to HTI.V-III, is associated with adult T-cell leukemia. And although no one knows if H'ILV-III has oncogenic potential, the mere possibility makes a whole-virus vaccine unnecessarily risky.

"Theoretically it should be possible to make a cloned subunit vaccine from the surface glycoprotein of viruses like LAV/HTLV-III," explains William Hardy of Sloan Kettering. "People have shown that purified surface proteins are immunogenic in the mouse and feline systems." In fact, cloning and expressing the surface protein of the virus, which presumably contains the major antigenic: sites, may be the easiest part of creating an AIDS vaccine.

Recent success with subunit vaccines prepared by genetically engineering cells to produce hepatitis $B$ and herpes glycoproteins has generated a lot of optimism. However, until it is clear that the subunits can elicit neutralizing antibodies, and that the antibodies can protect the immunized person against AIDS, the disease will continue to proliferate.

Most AIDS victims are either male homosexuals, who appear to contract the disease sexually, or intravenous drug users, who probably contract it via contaminated drug paraphernalia. However, much of the concern about an AIDS epidemic stems from the fear of contaminated blood supplies. 'Ihis fear should shortly be quelled because a simple screening test for exposure to the virus will soon be available.

Both American and French AIDS research groups have developed assays that detect antibodies to LAV/HTLV-III in blood. Antibody-positive status means the person has been exposed to the virus and may harbor an active infection. DHHS hopes to make the test available quickly and has granted licenses to five American companies for manufacture of the assay. Montagnier reports that Institut Pasteur Production, the commercial arm of the institute, will probably produce a test for IAV antibodies, but they have not announced specific details.

Immediate targets for the test include Factor VIII concentrates-used to control hemophilia-and blood supplies in places where AIDS is prevalent. Public health officials hope that the assay will be mass produced and added to routine blood testing. If the testing program is effective, it will eliminate one important route for transmission of AIDS, contaminated blood and blood products. While screening blood supplies for exposure to the virus reduces the risk that an AIDS epidemic will afflict the general population, it will not solve the AIDS problem. First, no one knows how many people have already been exposed to the virus. The long incubation period between infection and disease may mean that new victims will be turning up for years to come. The screening test will identify individuals exposed to the virus, but it may not be definitive for predicting AIDS. Most patients with AIDS or a less severe immune deficiency known as pre-AIDS have antibodies to the virus, but so do some apparently healthy high-risk individuals. Until long-term epidemiological data are available, researchers won't know if these people are destined to become AIDS victims.

The sudden appearance of AIDS in developed countries, coupled with its insidious destruction of the immune system, has made it one of the most fearsome diseases in recent years. People responded to the disease-and its hapless victims-emotionally, with alarm, loathing, and in some cases a sense that it is divine retribution. The optimistic prognostications of U.S. public health offcials-a screening test on the market in six months and a vaccine ready for testing in less than three years-may be an equally emotional response to identification of the AIDS infectious agent. But if the researchers can dispose what the government proposes, the natural history of AIDS may be astoundingly bricf. 